\title{
HYDROPOWER DAM SITE SELECTION AND VISUALIZATION USING GIS AND RS TECHNIQUES: A CASE OF MARINDUQUE, PHILIPPINES
}

\author{
R. M. A. Fesalbon ${ }^{1}$, A. C. Blanco ${ }^{1,2}$ \\ rafesalbon@up.edu.ph, acblanco@up.edu.ph \\ ${ }^{1}$ Department of Geodetic Engineering, University of the Philippines, Diliman, Quezon City \\ ${ }^{2}$ Training Center for Applied Geodesy and Photogrammetry, University of the Philippines
}

\section{Commission IV}

KEY WORDS: Renewable Energy, Valley Determination, Reservoir, Volume Computation

\begin{abstract}
:
The energy supply of the Philippines is dwindling considering rapid population growth, thus the need to maximize the advantages of harnessing renewable energy (RE) and optimizing its utilization in the grid. One of the RE sources that is considered practical due to its availability is running water, thus the development of hydropower. The use of remote sensing (RS) datasets and geographic information system (GIS) techniques are useful for pre-feasibility studies of hydropower development. This study utilizes Interferometric Synthetic Aperture Radar (IFSAR) - derived DEM, GIS-based hydrology and terrain characterization tools to identify natural reservoirs, and spatial analysis identify site for possible dam development. The methodology consists of two processes: valley determination, a component of landform classification, and flow accumulation. Different valley determination algorithms are included in the comparison analysis such as Multi-Resolution Valley Bottom Flatness (MRVBF), Topographic Position Index (TPI), Valley and Ridge Detection (VRD) and Geomorphons, with the latter best describing the valleys within the Marinduque island. The identified valleys are intersected with sites having the most suitable elevation, slope and flow accumulation. The results of the study are different indicative sites for hydropower development, the volumetric capacity for which are generated given design specifications (e.g. different dam heights). Furthermore, upon computing the volume of water that the reservoir can contain, the reservoir design is represented as three-dimensional features over the terrain to visualize the dam development.
\end{abstract}

\section{INTRODUCTION}

In the Philippines, the Department of Energy (DOE) has recognized the benefits of utilizing renewable energy such as energy security, the improvement in electricity costs, promotion of rural development, and generation of employment. On the other hand, DOE has also identified the challenges that the country encounters before fully integrating the use of renewable energy in the system such as the technology costs given that the utilization of these forms of energy require the use of innovative systems, the non-competitiveness and non-viable markets given that these systems have yet to prove bankability and sustainability, and the social acceptability of these systems especially in rural areas. To address these issues, the Philippine government is putting up policies in place to accommodate these challenges and support the development of renewable energy systems in the grid and off-grid (Delos Santos, A.A. - DOEREMB). One significant law to the cause is Republic Act No. 9513 or the Renewable Energy Act of 2008. This law supports the exploration and development of renewable energy resources, institutionalized the development of national and local capabilities in the use of renewable energy systems, supports the development of these resources as prevention or reduction of harmful emissions for economic, health and environmental development and aims to establish mechanisms to develop these systems, such as the introduction of fiscal and non-fiscal incentives (RA 9513, 2008). This law functions in conjunction with the Presidential Decree No. 40 which establishes the basic policies for the electric power industry (as amended by Executive Order No. 215 allowing the private sector to generate electricity), with the Republic Act No. 6957 which authorizes the financing, construction, operation and maintenance of infrastructure projects by the private sector and for other purposes and with the Republic Act No. 9136 or the Electric Power Industry Reform Act of 2001 (EPIRA) which ordains the reforms in the electric power industry to achieve the total electrification of the country (DOE, 2019; RA 9136, 2001).

This study focuses on the development of hydropower resources. Hydropower is the energy generated through moving water and is one of the most reliable resources given its availability and dependence on the water cycle that is consistently driven by the energy from the sun. According to the International Renewable Energy Agency (IRENA), hydropower produces approximately $16 \%$ of the world's electricity and $80 \%$ of the world's renewable electricity. This resource is considered the most flexible in responding to demand fluctuations, in delivering base-load power and in energy storage (IRENA, 2012).

According to the report from Asian Development Bank (ADB), the demand for electricity is projected to increase by $6 \%$ from 2008 to 2014 thus requiring an additional 4,000 MW of new generation capacity. By 2012, shortages are expected in the Luzon and Visayas grids as demand growth will catch up with the excess generation capacity in 2009 (ADB, 2009). The primary objective of this research is to develop a methodology to determine possible reservoir or dam sites for hydropower generation to assist in addressing the increasing need for energy supply. The application of RS and GIS techniques for determining potential sites for hydropower reservoir development may be considered efficient since it provides an initial assessment of the site. This assessment may serve as a reference for further technical analysis and engineering designs for hydropower plants. The possible sites are aimed for small reservoir-type hydropower plants with mini-hydro to small hydro plant capacities to minimize the environmental impact that a large dam may have in the vicinity of the inundation area. Small reservoir-type plants take into consideration the physical factors such as the terrain of the study area, the set-up whether the area can connect to the grid or can sustain a community through an off-grid connection, environmental factors such as the protected 
areas, forests, mining sites and other features, the economic factors such as the communities within the vicinity, possible transmission line connection and so on.

\subsection{Study Area}

Marinduque, as shown in Figure 1 below, is one of the island provinces of the Region IV-B located at 13-23-11 N, 121-58-16 $\mathrm{E}$ in the middle of the archipelagic country, with an approximate area of 95,925 hectares as reported by the Department of Environment and Natural Resources (DENR).

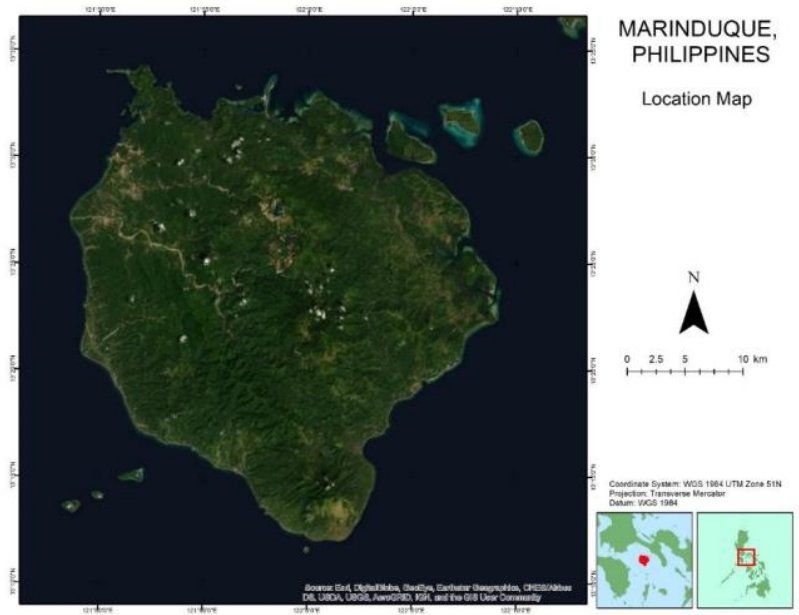

Figure 1. Marinduque Island, Philippines

The general topography of the province is hilly and mountainous with rolling and steep slopes (Salvacion and Magcale-Macandog, 2015). Based on the Philippine Statistics Authority (PSA, 2015), the province consists of six municipalities, namely Boac, Gasan, Buenavista, Sta. Cruz, Torrijos and Mogpog, and 218 barangays with 38,079 hectares of farms by land use. The island is separated from the Luzon mainland by the Mompong Pass and the Tayabas Bay. Based on the Environment and Natural Resources (ENR) statistical profile on the province, the province has $77 \%$ of alienable and disposable land covering 73,720 hectares and $23 \%$ of forest land covering 22,205 hectares. The prevailing climatic condition is type IV where rainfall is evenly distributed throughout the year with no clear boundary between dry and wet seasons. The mean annual temperature is at 27 degrees Celsius with the maximum at 32.9 and minimum at 22.3 degrees Celsius. Annual mean relative humidity is at $83 \%$ with the minimum of $78 \%$ usually in April and maximum of $86 \%$ in September to November. In terms of rainfall, the shore area of the island has approximately $2,000 \mathrm{~mm}$ of annual rainfall while the interior areas of the island have an approximately $3,500 \mathrm{~mm}$ of rainfall, with the average of $2,800 \mathrm{~mm}$ - majority of which occurs during the period of June to December. It should be noted that the amount of rainfall always fluctuated every year.

According to the Power Supply Procurement Plan (PSPP) of the Marinduque Electric Company, Inc. (MARELCO), the status of electrification of the province indicates that 388 out of the 408 potential sitios are energized as of 2017. The mandate of MARELCO is to provide electric service in the province with a total length of overhead distribution line of 16,641.652 circuit kilometers consisting of the following configurations: three phase (with 453.537 kilometers), v-phase (with 20.54 kilometers), single phase (with 383.03 kilometers), open secondary (with 431.965 kilometers) and under-built configuration (with 352.58 kilometers). Majority of the consumers of MARELCO consists of residential customers with
$90.72 \%$ of the total customers, followed by commercial consumers, public buildings, industrial consumers, water system and lastly, streetlights. The PSPP has a Distribution Impact Study (DIS) indicating that the generation and distribution of the province is composed of five embedded generators (located in the port of Barangay Balanacan, Mogpog, in Barangay Bantad, Boac, in Barangay Cagpo, Torrijos, in the Maniwaya islet and in the Mongpong islet), two sub-transmission line rated at $69 \mathrm{kV}$ and two substations - one is the 10 MVA substation located at Barangay Bantad that is connected to another $69 \mathrm{kV}$ line going to the 5 MVA substation at Barangay Cagpo, Torrijos. Based on the report, there are three identified economic locations of new power plants namely barangay Bantad in Boac, in the municipality of Sta. Cruz and in the boundary of Gasan and Buenavista. Based on the current datasets, the DOE has five ongoing applications for run-of-river systems namely the Boac, Tumagabok, Hinapulan, Cabuyo and Makulapnit Hydroelectric Power Projects.

\subsection{Related Studies}

Dam site selection is the process of incorporating different criteria in order to come up with suitable locations for certain types of dams and reservoirs. The study by Voivontas et al (1998) evaluates renewable energy potential through a GIS Decision Support System (DSS). In this study, a GIS database consisting of data on wind, topography, urban areas and special activities has been developed for the assessment of theoretical potential through spatially continuous mapping. The available and technological potential are assessed through the application of restrictions while the economic potential is evaluated using a precise estimation of the expected energy output and installation cost. The spatial distribution of renewable energy sources, the dependence of these resources on site specific characteristics and the overall cost dependence on spatial attributes are highlighted as the advantages of utilizing GIS for energy management. In this study, GIS is the introduced framework for incorporating all the regional social and geographical characteristics because of the system's flexibility in handling data available on different levels of spatial analysis and the capability to highlight spatial interrelations between datasets. The GIS-based DSS is developed in MAPINFO Professional, a GIS environment like ArcGIS (Voivontas, 1998).

Ghazal and Salman explore the optimum site of small dams using RS techniques and GIS. In their study, the drainage pattern and slope map are complemented by the geological map and Landsat satellite imagery from which the lineament structures were extracted. The lineaments are areas that are considered impediments in dam site development and should be avoided. On the other hand, criteria for consideration of dam site selection include areas of minimal slope for water collection and streams of high order to collect more volume of water (Ghazal and Salman, 2014).

Salih and Al-Tarif used GIS spatial analyses to explore the selected location of dam reservoir in Iraq. In this study, the primary considerations include the morphometric parameters and drainage pattern of the valley watershed. The watershed of the selected dam location is generated and the maximum level for every reservoir is determined. Different geometrical parameters are also generated using GIS (Salih and Al-Tarif, 2012).

One of the primary considerations for dam site selection is the terrain and if the location has a valley-shaped topography. Valleys are significant terrain features since these are usually the zones of transport for different materials and shelter from winds moving across the axis when cold air drainage passes through. 
They are considered as specific areas where the structure of the surrounding terrain can support a barrier for river flow restriction and control, creating a reservoir. Valley determination is a process that identifies areas that can be considered as valleys based on the DEM. Valleys are identified as one of the geomorphic features of the surface or those terrain features the shapes of which are brought about by the continuous geological changes. Other features include the peaks, troughs, mountainous areas, flat lands, and so on.

In most of the literatures on valley determination, GIS and RS are utilized in the processes. The study by Gallant and Dowling highlights the correlation between the valley bottom flatness to the depth of sediment deposits and to groundwater constrictions, therefore delineating significant hydrologic and geomorphic units given a DEM. The developed algorithm MRVBF is dependent on parameters namely the slope thresholds, resolution ratio and nonlinear functions, that involve arbitrary choices and may be refined depending on the terrain characteristics and the input data. The algorithm identifies valley bottoms using the assumptions that these features are low and flat relative to their surroundings, they occur at a range of scales and that large valley bottoms are flatter than smaller ones. Implementation of the algorithm involves a slope classification constrained to convergent areas applied at multiple scales by progressive generalization of DEM combined with progressive reduction of slope class threshold. The results are then combined into a single index (Gallant and Dowling, 2003). Based on the study by Wang and Laffan, there are two approaches to valley identification the first one is the application of flow accumulation indices for identification of channel network and hillslopes from which valleys can be extracted, the second one is the use of the MRVBF to identify flat valley bottoms. However, in their study, they have developed a new method for valley identification, the MultiScale Valleyness (MSV) Index, by fitting a quadratic surface over the DEM to derive indices describing the fuzzy memberships to the peakness, pitness, passness, ridgeness and valleyness. (Wang and Laffan, 2009). The study by Schmidt and Hewitt indicates that typical landform properties used in describing land elements are local geometry (which may be described by the terrain vicinity concavity or convexity and such), form and size (which takes into consideration the scale and spatial extent), topological attributes (or those that characterize the neighborhood of the subject area) and the surface roughness. (Schmidt and Hewitt, 2004).

Another method is the TPI wherein the algorithm compares each cell in a DEM to the average elevation of a specified neighborhood around that cell such that the mean elevation is subtracted from the elevation value at the center (Mokarram, 2015). Positive TPI values indicate locations with higher than average of the local window or are ridges and negative TPI values indicate locations with lower than the average of the local window indicating valleys. Those areas with TPI values near zero indicate flat areas or areas with constant slope (Seif, 2014).

Rodriguez, et al have implemented the Black Top Hat function in VRD that allows the extraction of peaks and valleys of a given size depending on the size of the chosen structural element. When no threshold is applied, the method considers all valleys thus leading to a more precise estimation of the total incised volume. This function is an adaptive filter independent from local altitudes thus allowing the simulation to fill up valleys whose lengths are equal or inferior to the size of the structuring element independently of their relative topographic location. This function enhances the valley bottoms (Rodriguez, 2002).
Another approach is the identification of Geomorphons wherein the function generates a comprehensive and exhaustive set of idealized landforms that are independent of size, relief and orientation of the actual landform, as described by Stepinski and Jasiewicz (2011). Based on their study, landform mapping has the following principles - morphologic, genetic, chronologic and dynamic. The basic steps for landform automatic mapping involve the description of landform elements in terms of numerical features such as differential geometry, slope gradients and types of curvature which are implemented usually through a scale-dependent moving window, and the semantic assignment or the description using landform-like names. However, their study has developed Geomorphons such that the process departs significantly from all existing methodologies with the following core components - first, the method generalizes an image analysis concept of local binary patterns to local ternary patterns and secondly, the process utilizes a line-of-sight neighborhood to achieve flexibility in sizes of mapped landforms. Since the approach implements the line-of-sight principle, it relates the zenith and nadir angles of the surface relief along eight principal directions and the ternary operator converts the said information contained in all the pairs of the zenith and nadir angles into the ternary pattern. The result of each simulation depends on two parameters: the search radius or the maximum allowable distance for calculation of the zenith and nadir angles, and the relief threshold or the minimum value of the angle (zenith or nadir) considered significantly different from the horizon (Stepinski and Jasiewicz, 2011).

Kramm, et al have developed an accuracy assessment for landform classification approaches on different spatial scales The approach of Dikau is a stepwise classification that is subdivided in the derivation of slope, local relief and profile type classifications using slope, focal statistics and algebra, and the reclassification scheme from derived landform subclasses to final landform classes. TPI utilizes an annulus with an inner and outer cell radius the values of which are selected based on the pixel resolution of the data. The object-based approach initially calculates the slope and curvature as further input dataset for the segmentation implemented in eCognition by the multiresolution segmentation tool. Lastly, the Geomorphons approach compares height values of cells in eight different directions to the regarding cell and utilizes input parameters for an inner and outer search radius to set the distance for the calculation of height differences or those calculated after the line-of-sight principle. The methodology for accuracy assessment includes the field campaign of 314 DGPS for ground truth capture and comparison of the processing results. The classified landscape can be divided into three general landform elements - the flat areas, valleys and hills. The study presents the overall accuracy of the four approaches and the four difference datasets derived as the relation of correctly classified to all classified elements from the confusion matrices. Based on the study, the classifications of TPI and Geomorphons provide the best visual feedback of the landscape structure due to the spatially accurate classification of landforms. TPI seems the most suitable for a meaningful classification as it has the greatest class diversity for the classification of hills, hillslopes and valleys. However, it has some weaknesses in flat landscapes due to very inhomogeneous classification of these areas with high pixel resolution datasets. On the other hand, the Geomorphons approach achieves higher accuracy in the classification of plains and valleys. However, the approach classifies the structures of hilly landforms less detailed compared to TPI although the number of suitable classes is similar (Kramm, 2017). 

Table 7. Overall accuracy of the four approaches and the four different datasets derived as the relation
of correctly classified to all classified elements from the confusion matrices (Tables $\mathrm{A} 1-\mathrm{A} 4$ ).

\begin{tabular}{ccccc}
\hline & $\mathbf{5 ~ m}$ & $\mathbf{1 0 ~} \mathbf{m}$ & Aster 30 m & SRTM 30 m \\
\hline Dikau & $63 \%$ & $58 \%$ & $33 \%$ & $42 \%$ \\
TPI & $72 \%$ & $71 \%$ & $44 \%$ & $41 \%$ \\
Object-based & $63 \%$ & $63 \%$ & $42 \%$ & $40 \%$ \\
Geomorphons & $70 \%$ & $65 \%$ & $39 \%$ & $39 \%$ \\
\hline
\end{tabular}

Table 1. Results of the accuracy assessment performed by Kramm (2017)

\section{METHODOLOGY}

In order to determine the optimum dam site for hydropower development, a methodology utilizing RS and GIS is developed. Initially, the location based on the flow accumulation and valley determination algorithm is determined since based on literature, these are two of the primary considerations for reservoir development. Different valley determination algorithms are explored for the purpose of this study in order to determine the most applicable one given the terrain and the available datasets. Flow accumulation is applied to determine the number of cells contributing to the drainage of the watersheds within the study area.

\subsection{Input data}

The primary data for the study is the DEM. The DEM used in this study is derived from IFSAR with a 5-meter resolution. This data is used for majority of the terrain-related analyses including the valley determination, flow accumulation, morphometric analysis, hydrologic modelling and reservoir capacity computation. The DEM is masked to focus on the study area.

\subsection{Valley Determination}

Valleys are the conducive landform on which dams can be best located. The natural terrain of these locations allows the structural requirements of the dam to be constructed with more support and stability. Therefore, further investigation is conducted in the most appropriate method to determine valleys using DEM.

The first method is the MRVBF which identifies valley bottoms with the assumption that these features are naturally low and flat relative to their surroundings, that these features occur at a range of scales and that large valley bottoms are flatter than smaller ones. The algorithm behind this method identifies valley bottoms using slope classification constrained to convergent areas and applied at multiple scales by progressive generalization of DEM combined with progressive reduction of slope class threshold. This method is implemented using SAGA GIS. MRVBF requires the elevation model as the primary input and the following parameters as optional inputs: the initial threshold for slope, the threshold for elevation percentile for lowness, the threshold for elevation percentile for upness, the shape parameter for slope, the shape parameter for elevation percentile, the option to update the views, the option for classification and the maximum resolution in terms of percentage. According to Gallant, MRVBF is a continuous measure that is usually divided into classes corresponding to the different resolutions and slope thresholds such that values less than 0.5 are not valley bottom areas, values 0.5-1.5 are considered to be the steepest and smallest resolvable valley bottoms for 25-m DEMs, and flatter and larger valley bottoms are represented by values $1.5-2.5,2.5-3.5$ and so on. The values in the resulting process ranges from 0 to 6 with 6 showing the areas with flatter and larger valley bottoms (Gallant and Dowling, 2003).

The second method, also implemented using SAGA GIS, is the TPI which has similarities with the calculation of difference to the mean or residual analysis. In this method, the bandwidth parameter for distance weighting is given as the percentage of the outer radius. TPI values near zero are either flat areas where the slope is near zero or areas of constant slope where the slope of the point is significantly greater than zero.

The third method is the VRD which utilizes a top-hat transform function - a gray-level image analysis tool that allows extracting peaks and valleys in a non-uniform background. This method is implemented in SAGA GIS as well.

Lastly, the fourth method explored in this study is the application of Geomorphons. The results are geomorphologic phenotypes characterized by local ternary patterns that serve as archetypes of specific terrain morphology - patterns use neighborhood analysis with size and shape that self-adapts to the local topography using the line-of-sight principle. This method is implemented using GRASS GIS.

Comparison of the results of these methods is analyzed and the applied method is the Geomorphons as the identified valleys are closest to the valleys based on satellite imagery. The algorithm for Geomorphons is run for 10 iterations, adjusting the outer search radius and the flatness distance. The results are then reclassified based on the values that best describes valleys.

\subsection{Flow Accumulation and Dam Selection}

Flow accumulation is implemented using ArcGIS Spatial Analyst toolbox, specifically the hydrology tools. The resulting data from the flow accumulation tool is then reclassified to extract those characterizing streams such as those with cell accumulation of more than 100,000 .

When the valleys are identified, the criteria for dam selection common to most references are that locations are valleys with maximum flow accumulation for sufficient water volume, located on higher elevations with relatively flat slope to accommodate a reservoir that will be least subjected to flooding. Given these references, a ModelBuilder tool is developed to incorporate these criteria and extract points that may be considered as dams. There are four primary inputs in the tool are the flow accumulation raster, the valley raster, the slope raster and the IFSAR DEM. The identified valleys are extracted from the valley layer. The elevation and the slope of the valley areas are then extracted from the DEM and slope raster, respectively. The flow accumulation is generated using the hydrology tools in ArcMap - following the process of filling the DEM sinks, generating the flow direction and generating the flow accumulation. The resulting flow accumulation raster is then subjected to reclassification such that only those pixels with accumulation value of 100,000 or more are necessary for the process. Reclassification is also applied to the elevation layer of the valleys wherein the elevation layer is classified into two following an equal interval and the class with higher elevations are extracted. Reclassification is applied to the slope layer such that only those with slope values of $0-5$ percent are extracted. The reclassified flow accumulation, valley elevation and valley slope data layers are then combined. The resulting points are then aggregated in order to define point clusters satisfying the criteria. Once clusters are identified, the summary statistics of the points per cluster is generated in order to determine the point with the most volume of water accumulation among the pool. One point per cluster is identified as the possible dam site location. 


\subsection{Indicative Dam Heights and Capacity}

Different dam heights are simulated for each of the three selected possible dam locations. The dam location is initially drawn and given a theoretical dam height for computation. The dam crest is also represented using the height of the riverbed such that a threedimensional representation of the dam design is provided. The plane representing the dam height is also drawn in order to identify the inundation area of the terrain. The dam design and dam height plane are then converted into TIN datasets. The polygons affected by the dam design and the inundation area are then extracted and converted to raster datasets. These raster datasets are then given the corresponding elevation information - the dam design height and the terrain elevation of the inundated area - and then converted to the TIN dataset that represents the theoretical reservoir of the indicated dam.

In order to accomplish the volume computation, a set of ModelBuilder tools is developed - one for generating the preliminary layers for volume computation and one for the generation of reservoir triangulation irregular network (TIN) and corresponding report. In the first tool, the primary inputs are the IFSAR DEM, the features representing the dam (including the dam height, crest and base) and the features representing the possible areas affected by the dam. The features representing the dam have the corresponding elevation for the base and the dam height. The features representing the dam area are given the value of the dam height. And these features are drawn perpendicular to the direction of the indicative streamflow. The TIN for the terrain is generated, as well as that for the design dam and the dam height surface. The elevation of the design dam intersecting with the area affected by the dam is given data points. The rest of the areas affected by the dam surface is given the terrain data points. Combining the two sets of data points - design dam elevation and inundation surface elevation - generates the volume that the possible reservoir the dam may create. The second tool then utilizes these data points and creates the reservoir with the corresponding report on the surface area and volume. Multiple theoretical reservoir representations are generated to simulate the inundation areas of different dam heights that can aid in site optimization and decision-making.

\section{RESULTS AND DISCUSSIONS}

This study highlights the process of locating the optimum dam site for hydropower development. The onset of the process is the valley determination - taking into consideration the geomorphology of the terrain and the corresponding landform classification. In this process, different methods are investigated to come up with the most applicable one. For MRVBF, the input elevation is the IFSAR DEM and the parameters are given the default value except for the initial threshold slope which is given the value of 32 following the premise of Gallant (2003) where the threshold of 64 is applied to a DEM with a three-meter resolution and a threshold of 128 is applied to a DEM with a onemeter resolution - the slope thresholds change by a ratio of 2 at each step following a geometric sequence. The result has an index range of 0-6 wherein the larger values indicate the valleys.

The second method explored in this study is the TPI-based landform classification. The primary input for the model is the IFSAR DEM, and the secondary input are parameters that are optional - thus the default values for the processing radii are adapted and no distance weighting is applied. TPI result indicates a range -1 to 9 which is classified such that the negative value indicates the valleys.
Another method investigated in this study is the VRD utilizing a top hat transform function implemented in SAGA GIS as well. The primary input in the process is the IFSAR DEM. Other optional parameters are the valley radius, hill radius, elevation threshold and slope index all of which adapted the default values. The results of the method include five datasets - valley index with values 0 to 1 indicating where the valleys are, valley depth with values ranging from 0 to 236 meters, hillslope index with values 0 to 1 indicating the slope, the hill index ranging from 0 to 1 indicating the possible locations of hills relative to the terrain data and the hill height ranging from 0 to 393 meters.

Lastly, Geomorphons approach is applied in order to generate the landform classification and therefore determine the valleys. The primary inputs for this approach are the IFSAR DEM, the outer search radius, inner search radius, flatness threshold and flatness distance. For this process, the approach is simulated ten times with varying parameters. The result is focused on classifications one through ten with values 9 and 10 indicating the valley and depression areas.

\begin{tabular}{|c|c|c|c|c|}
\hline VDA Approach & Qualification & \begin{tabular}{c|} 
Ide ntified as \\
Stre ams/Valleys
\end{tabular} & $\begin{array}{l}\text { Total Data } \\
\text { Points }\end{array}$ & $\%$ \\
\hline MRVBF & \begin{tabular}{|c|} 
Upper $3 / 4-$ Natural \\
Breaks with 4 \\
Classifications \\
\end{tabular} & 1603 & \multirow{13}{*}{3337} & 48.04 \\
\hline TPI & Negative values & 65 & & 1.95 \\
\hline VRD & \begin{tabular}{|c|} 
Upper $4 / 5$ - Natural \\
Breaks with 5 \\
Classifications
\end{tabular} & 1171 & & 35.09 \\
\hline Geomorphons 001 & \begin{tabular}{|c|} 
Values 9 (Valleys) \\
and 10 (Depression)
\end{tabular} & 949 & & 28.44 \\
\hline Geomorphons 002 & $\begin{array}{c}\text { Values } 9 \text { (Valleys) } \\
\text { and } 10 \text { (Depression) }\end{array}$ & 1232 & & 36.92 \\
\hline Geomorphons 003 & \begin{tabular}{|c|} 
Values 9 (Valleys) \\
and 10 (Depression)
\end{tabular} & 1232 & & 36.92 \\
\hline Geomorphons 004 & \begin{tabular}{|c|} 
Vahues 9 (Valleys) \\
and 10 (Depression)
\end{tabular} & 1255 & & 37.61 \\
\hline Geomorphons 005 & \begin{tabular}{|c|} 
Values 9 (Valleys) \\
and 10 (Depression)
\end{tabular} & 1696 & & 50.82 \\
\hline Geomorphons 006 & \begin{tabular}{|c|} 
Values 9 (Valleys) \\
and 10 (Depression)
\end{tabular} & 1753 & & 52.53 \\
\hline Geomorphons 007 & \begin{tabular}{|c|} 
Values 9 (Valleys) \\
and 10 (Depression)
\end{tabular} & 1739 & & 52.11 \\
\hline Geomorphons 008 & \begin{tabular}{|c|} 
Values 9 (Valleys) \\
and 10 (Depression) \\
\end{tabular} & 1734 & & 51.96 \\
\hline Geomorphons 009 & \begin{tabular}{|c|} 
Values 9 (Valleys) \\
and 10 (Depression) \\
\end{tabular} & 1743 & & 52.23 \\
\hline Geomorphons 010 & $\begin{array}{c}\text { Values } 9 \text { (Valleys) } \\
\text { and } 10 \text { (Depression) }\end{array}$ & 1742 & & 52.2 \\
\hline
\end{tabular}

Table 2. Comparison of results

Based on the study by Kramm, the two most applicable methods for landform classification are the TPI and Geomorphons approach. However, the classifications are more defined in the latter thus the application of the approach in this study. Furthermore, comparison analysis is performed to validate the selection. With the assumption that the valleys are usually identified as areas of flow accumulation, 3,337 random validation points are generated based on such areas. Using the results of the MRVBF, TPI, VRD and Geomorphons approaches, the number of data points that are identified as valleys is compared and analysed, generating the following results (Table 2). These findings make the Geomorphons approach the most applicable for the valley determination objective.

Upon determination of the valleys in the study area, the elevation and slope data are incorporated in order to determine the parts of the valleys that have a higher elevation and a relatively flat terrain to accommodate the volume of the reservoir. These criteria are incorporated in a ModelBuilder tool that identifies the qualified sites as pour points for the subsequent watershed delineation. The tool selects the qualified sites and clusters the sites that belong to the same tributary. The corresponding flow accumulation for each site is identified and sorted such that the sites with the most volumetric capacity that can be accumulated are selected for possible dam development. Ten sites are generated wherein six out of the ten sites are in Barangay Sibuyao in the Municipality 
of Torrijos, three are along the boundary of the same barangay, intersecting the boundary of Barangay Makulapnit, Municipality of Santa Cruz, Barangay Talawan in Torrijos and Barangay Tumagabok, Municipality of Boac. One of the ten sites is in Barangay Tumagabok as well. Five of these sites have a geologic structure from the Paleocene-Eocene period, mainly consisting of sedimentary and metamorphic rocks. One has an OligoceneMiocene geologic structure and the rest have geologic structures from the Paleocene-Eocene period consisting of igneous rocks. In terms of land cover, three out of the ten sites are located on open forests, three are on shrub covers, two are on wooded grasslands and two are on annual crop covers. In terms of soil, four of the selected points have the Banto soil series for the primary soil type, and the rest are on hydrosol type of soils.

Four possible scenarios for reservoir development are selected site 6 with two scenarios varying in dam height and site 9, both located in Barangay Sibuyao in Torrijos, and site 10 in Barangay Talawan in Torrijos. The TIN for the sites is generated to compute for and visualize the reservoir capacity, given the dam height scenarios. The processes for volume computation and reservoir generation are incorporated in ModelBuilder tools, respectively. The table below shows the consolidated computation for three of the selected prospective dam developments upon application of the above-mentioned tools.

\begin{tabular}{|c|c|c|c|c|c|c}
\hline Dam Site & $\begin{array}{c}\text { Base } \\
\text { Elevation }\end{array}$ & $\begin{array}{c}\text { Dam } \\
\text { Elevation }\end{array}$ & $\begin{array}{c}\text { Dam } \\
\text { Height }\end{array}$ & $\begin{array}{c}\text { 2D Area } \\
\text { (sq.m.) }\end{array}$ & $\begin{array}{c}\text { 3D Area } \\
\text { (sq.m.) }\end{array}$ & $\begin{array}{c}\text { Volume } \\
\text { (cu.m.) }\end{array}$ \\
\hline 6 & 310 & 350 & 40 & $26,900.60$ & $32,675.01$ & $336,183.10$ \\
\hline 6 & 310 & 400 & 90 & $150,625.20$ & $171,818.50$ & $3,787,710$ \\
\hline 9 & 370 & 395 & 25 & $140,590.60$ & $146,375.80$ & $996,195.70$ \\
\hline 10 & 315 & 345 & 30 & $65,526.47$ & $70,209.95$ & $682,519,10$ \\
\hline
\end{tabular}

Table 3. Results of volumetric computation

The tools are applied to the three locations with varying dam heights as applicable to the terrain. The resulting computations are then consolidated in order to compute for the power that the dam can generate, as shown in the table below, considering an overall plant efficiency of $87 \%$.

\begin{tabular}{|c|c|c|c|c|}
\hline Dam Site & $\begin{array}{c}\text { Mean } \\
\text { Discharg }\end{array}$ & $\begin{array}{c}\text { Dam } \\
\text { Height }\end{array}$ & $\begin{array}{c}\text { Crest } \\
\text { Length }\end{array}$ & $\begin{array}{c}\text { Power } \\
\text { (kW) }\end{array}$ \\
\hline 6 & 0.6118 & 40 & 130 & 207.9978 \\
\hline 6 & 0.6118 & 90 & 300 & 467.995 \\
\hline 9 & 0.4157 & 25 & 150 & 88.334 \\
\hline 10 & 0.6283 & 30 & 180 & 160.2171 \\
\hline
\end{tabular}

Table 4. Indicative power capacity with an efficiency of $87 \%$ overall

Based on the volumetric capacity of the indicative reservoir and the average simulated discharge on the indicative dam locations, the theoretical duration to sustain the design capacity to generate power is computed for each scenario, as shown in the table below.

\begin{tabular}{|c|c|c|c|c|c|c|c|}
\hline Scenario & Site & $\begin{array}{c}\text { Dam } \\
\text { Height }(\mathbf{m})\end{array}$ & $\begin{array}{c}\text { Crest } \\
\text { Length (m) }\end{array}$ & $\begin{array}{c}\text { Power } \\
\text { (kW) }\end{array}$ & $\begin{array}{c}\text { Mean } \\
\text { Discharge } \\
(\mathbf{c m s})\end{array}$ & $\begin{array}{c}\text { Volume } \\
\text { Capacity } \\
\text { (cu.m.) }\end{array}$ & $\begin{array}{c}\text { Duration } \\
\text { (days) }\end{array}$ \\
\hline 1 & 6 & 40 & 130 & 208 & 0.611758 & $336,183.13$ & 7 \\
\hline 2 & 6 & 90 & 300 & 468 & 0.611758 & $3,787,710.85$ & 72 \\
\hline 3 & 9 & 25 & 150 & 88 & 0.41569 & $996,195.72$ & 28 \\
\hline 4 & 10 & 30 & 180 & 160 & 0.628302 & $682,519.06$ & 13 \\
\hline
\end{tabular}

Table 5. Calculation of duration for volume capacity maintenance given the mean discharge for each scenario

The table reflects the minimum number of days that the average discharge must be retained in order to maintain the capacity of the reservoir. A conservative assumption for the reservoir sustainability in terms of capacity should incorporate the longterm pattern of discharge to manage the temporal variability and therefore apply appropriate scheduling in water release in the sluice gates to the turbines.

The maps of the possible dam locations and corresponding indicative reservoirs are given in the figure below.

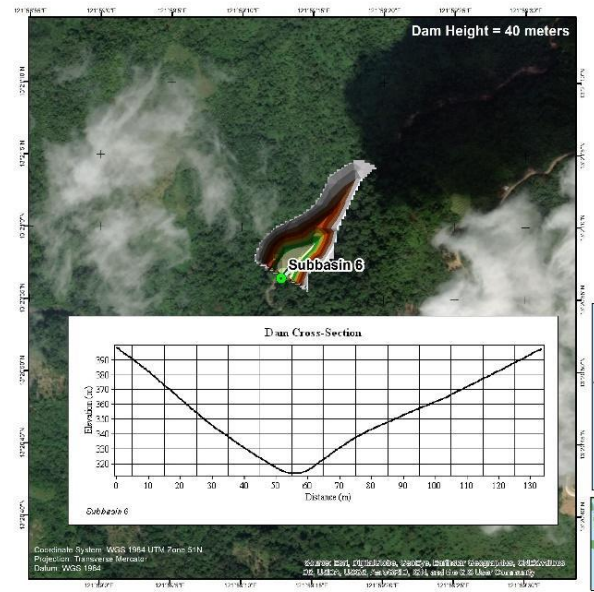

MARINDUQUE, PHILIPPINES

Legend

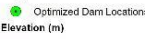

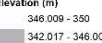

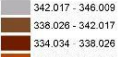
$330.043-334093$
326.052 .330 .043
$322.06-320.052$ $322.06-320.052$
$318.069 \cdot 322.06$
314.077
310.009

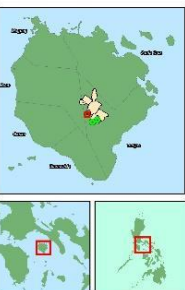

Figure 2. Map showing the indicative reservoir for dam site 6 with height of 40 meters
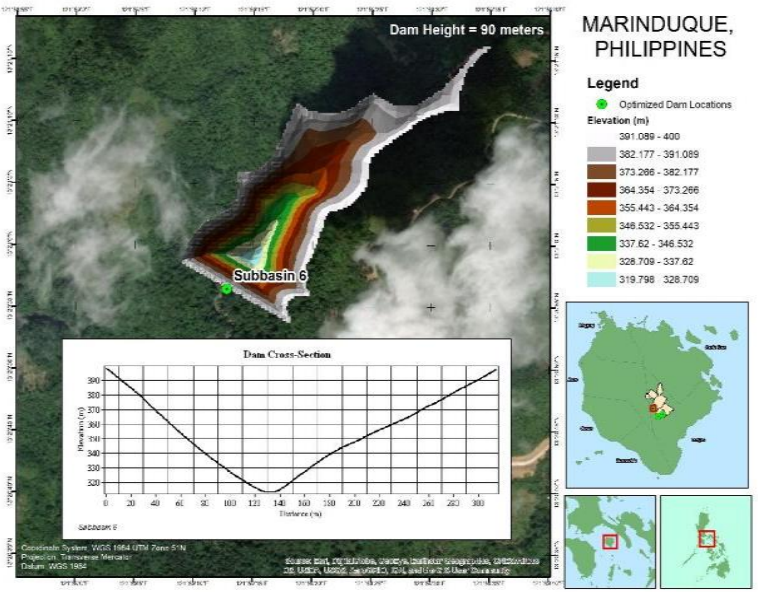

Figure 3. Map showing the indicative reservoir for dam site 6 with height of 90 meters

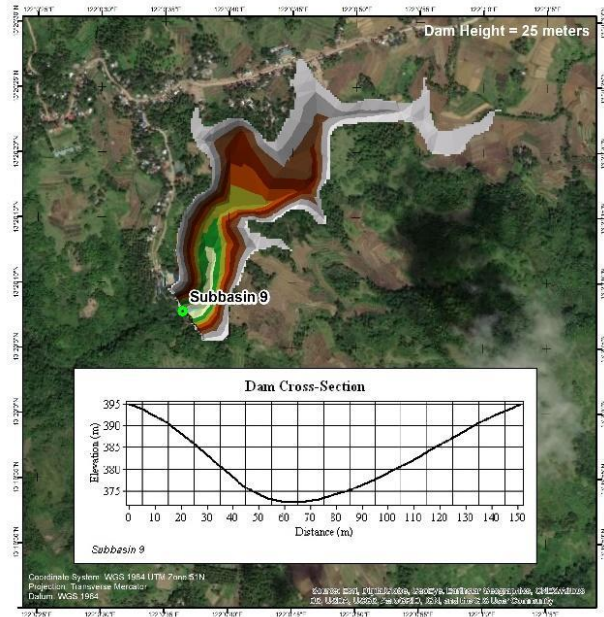

MARINDUQUE, PHILIPPINES

Legend Opotinized Derm Locations $392.244-395$

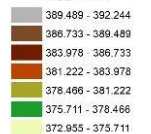
(370.190 37205

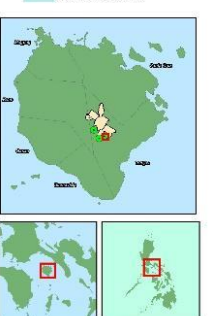

Figure 4. Map showing the indicative reservoirs for dam site 9 with height of 25 meters 


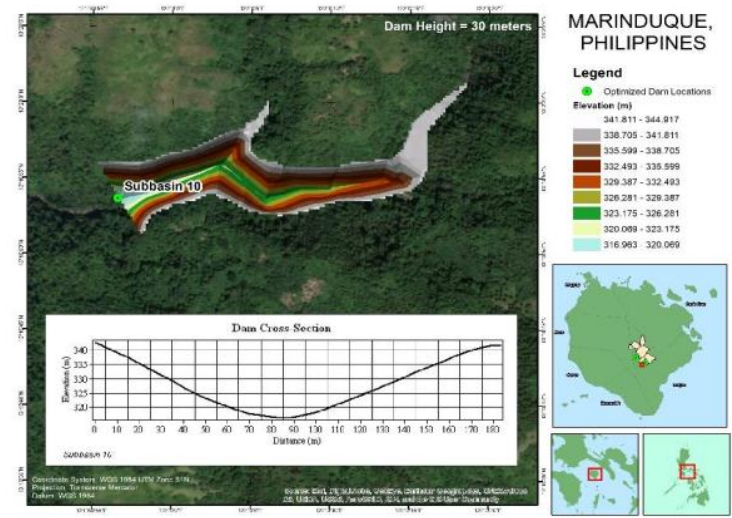

Figure 5. Map showing the indicative reservoirs for dam site 10 with height of 30 meters

Based on the results, it can be observed that of the 4 scenarios, scenario 3 (site 9) has the closest proximity to built-up areas, with a distance of at least 15 meters, thus deeming this site not suitable for hydropower development in terms of possible inundation, despite its proximity to the transmission line.

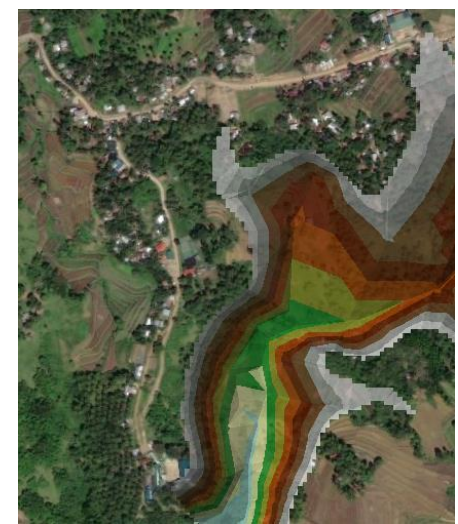

Figure 6. Proximity of indicative site to built-up areas - based on this map, it can be observed that parts of the reservoir extent are very close to the built-up areas with some are having a distance of at least 15-meters from the reservoir boundary

Based on the Household Energy Consumption Survey (2011), the average consumption per household is approximately $649 \mathrm{kWh}$ for a six-month duration making the monthly consumption to be $108.17 \mathrm{kWh}$. The table below shows the approximate energy consumption based on the uses within the households:

\begin{tabular}{|c|c|c|}
\hline End-Use & Ave. Consumption per Household (kWh) & $\begin{array}{c}\text { kWh per } \\
\text { month }\end{array}$ \\
\hline Lighting & 60 & 10 \\
\hline Cooking & 108 & 18 \\
\hline Water Heating & 484 & 80.67 \\
\hline Recreation & 129 & 21.5 \\
\hline Refrigeration & 390 & 65 \\
\hline Air Conditioning & 277 & 46.17 \\
\hline Ironing & 37 & 6.17 \\
\hline Laundry & 36 & 6 \\
\hline Water Pumping & 623 & 103.83 \\
\hline Computer Activity & 84 & 14 \\
\hline Other Appliances & 2 & 0.33 \\
\hline
\end{tabular}

Table 6. Average energy consumption per household for six months
Based on this information, the following computation is generated for the possible number of households that the indicative reservoir can provide energy to.

\begin{tabular}{|c|c|c|c|c|c|c|}
\hline Dam Site & $\begin{array}{c}\text { Dam Height } \\
\text { (m) }\end{array}$ & Power $(\mathrm{kW})$ & $\begin{array}{c}\text { Energy } \\
\text { (MWh per } \\
\text { year) } \\
\end{array}$ & $\begin{array}{c}\text { kWh per } \\
\text { month }\end{array}$ & $\begin{array}{l}\text { kWh per } \\
\text { House hold }\end{array}$ & $\begin{array}{c}\text { No. of } \\
\text { Households }\end{array}$ \\
\hline 6 & 40 & 208 & 1822 & 149,758 & \multirow{4}{*}{108.17} & 1384 \\
\hline 6 & 90 & 468 & 4100 & 336,956 & & 3115 \\
\hline 9 & 25 & 88 & 774 & 63,600 & & 588 \\
\hline 10 & 30 & 160 & 1403 & 115,356 & & 1066 \\
\hline
\end{tabular}

Table 7. Demand analysis

With the conservative assumption of having a $108.17 \mathrm{kWh}$ monthly consumption per household, the first scenario can energize 1,384 households, the second one can energize 3,115 households, the third can energize 588 households and the fourth scenario can energize 1,066 households. The assumed value for the monthly consumption may be decreased should households be located in rural areas or on islands such as the study area and therefore, the above-mentioned scenarios may cater to more communities than those indicated in the table.

The scenarios can generate approximately $924 \mathrm{~kW}$ which can provide electricity to more than 6000 households. Scenario 2 has the largest reservoir capacity and therefore has to have 72 days or more than two months to maintain the volume given the simulated discharge and generate the computed power. Scenario 1 has the smallest reservoir thus requiring only 7 days to maintain the volumetric capacity. Since the suitability of the dam location, a more appropriate design dam may be applied in order to maximize the capacity and the maintenance duration in order to cater to the demand.

\section{CONCLUSION AND RECOMMENDATIONS}

4.1.1 The development of renewable energy systems is becoming more significant as the need for energy arises. Renewable energy is a resource that may be advantageous in many aspects should the resource be harnessed strategically. One of the renewable energy resources abundant in the Philippines is water and the utilization of water in order to generate hydropower may be beneficial especially to areas with limited power supply such as on islands. This study has developed a methodology to find optimum sites for dam development in the island of Marinduque using multiple techniques utilizing RS and GIS.

The methodology is the valley determination, supplemented by elevation and slope, as a subcomponent of landform classification, thus satisfying the criterion that dam sites are located on valleys such that the natural terrain structure may be suitable for dam and reservoir development. Four valley determination approaches are investigated in this study. Based on related literatures and assessment performed in this study, the selected approach is the Geomorphons. Tools are developed for dam site selection based on the terrain and for the volume computation and the data consolidation in order to generate the final database of the selected sites for comprehensive prefeasibility study. Based on the results, it can be concluded that GIS and RS are advantageous in identification of possible reservoir site for hydropower plant development since these locations are heavily dependent on terrain configurations. The methodology characterizes the topography and generates locations based on the indicated criteria, as well as the features of the locations for reference of subsequent studies. The island of Marinduque has potential for hydropower development based on the physical characteristics and may be increased should the study be extended to more detailed feasibility assessments taking 
into consideration other factors such as social and environmental. Moreover, it is recommended that different dam types also be considered to further optimize the site selection scheme.

\section{REFERENCES}

Asian Development Bank, Philippine Energy Efficiency Project, Asian Development Bank, (January 2009)

Delos Santos, A. S. A., Renewable Energy in the Philippines, Renewable Energy Management Bureau, Department of Energy, Philippines

Department of Energy and National Statistics Office, Household Energy Consumption Survey - Final Report, Department of Energy and National Statistics Office, (2011)

Gallant J. C. and Dowling T. I., A Multi-Resolution Index of Valley Bottom Flatness for Mapping Depositional Areas, Water Resources Research, Vol. 39, No. 12, 1347, Canberra, Australia (2003)

Ghazal, N. K. and Salman, S. R., Determining Optimum Site for Small Dams Using RS Techniques and GIS, International Journal of Scientific Engineering and Research (IJSER), Baghdad, Iraq (2014)

Governing Laws and Issuances - DOE Portal, Retrieved from www.doe.gov.ph, (2019)

International Renewable Energy Agency, IRENA - Hydropower, IRENA, (June 2012)

Kramm, T., et.al., Accuracy Assessment of Landform Classification Approaches on Different Spatial Scales for Iranian Loess Plateau, ISPRS International Journal of Geo-information Vol. 6 No. 366, (2017)

MARELCO PSPP 2018-2027, Department of Energy, Philippines (2019)

Mokarram, M., et.al., Landform Classification Using Topography Position Index, Model. Earth Syst. Environ. (2015) 1:40, International Publishing Switzerland, (December 2015)

Power Statistics as of March 29, 2019 (Summary), Department of Energy, Philippines (2018)

RA 9136 - EPIRA Law, Philippines (2001)

RA 9513 - Renewable Enery Act, Congress of the Philippines, Philippines (2008)

Rodriguez, F. et.al., The Black Top Hat Function Applied to a DEM - A Tool to Estimate Recent Incision in a Mountainous Watershed, Geophysical Research Letters, American Geophysical Union Volume 29 No. 6, (2002)

Salih, S. A. and Al-Tarif A. S.M., Using of GIS Spatial Analyses to Study the Selected Location for Dam Reservoir on Wadi AlJirnaf West of Shirqat Area Iraq, Journal of Geographic Information System 4, 117-127, Tikrit, Iraq (2012)

Salvacion, A. R. and Magcale-Macandog, D. B., Spatial Analysis of Human Population Distribution and Growth in Marinduque Island Philippines, Journal of Marine and Island Cultures 4, 27 $33,(2015)$
Schmidt, J. and Hewitt, A., Fuzzy Land Element Classification from DTMs Based on Geometry and Terrain Position, Geoderma 121: 243-256, (2004)

Seif, A., Using Topographic Position Index for Landform Classification, Bulletin of Environment, Pharmacology and Life Sciences Volume 3 [11]: 33-39, India (October 2014)

Stepinski, T. F. and Jasiewicz, J., Geomorphons - A New Approach to Classification of Landforms, Geomorphometry.org, (2011)

Voivontas, D. et.al, Evaluation of Renewable Energy Potential Using a GIS Decision Support System, Renewable Energy Vol. 13, No. 3, pp. 333-344 (1998)

Wang D. and Laffan, S. W., Characterization of Valleys from DEMs, 18th World IMACS/MODSIM Congress, Cairns, Australia (July 2009)

Revised May 2019 